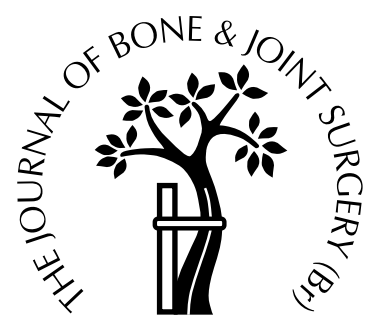

\title{
Open-wedge osteotomy by hemicallotasis or the closed-wedge technique for osteoarthritis of the knee
}

\author{
A RANDOMISED STUDY OF 50 OPERATIONS \\ G. Magyar, T. L. Ahl, P. Vibe, S. Toksvig-Larsen, A. Lindstrand \\ From the University Hospital, Lund, Sweden
}

W e describe the results of 50 operations carried out on 46 patients with medial osteoarthritis of the knee of Ahlbäck grade 1 to 3. Patients were randomised either to a closed-wedge high tibial osteotomy (HTO) or an open-wedge procedure based on the hemicallotasis technique (HCO). Their median age was 55 years (38 to 68). The preoperative median hip-knee-ankle (HKA) angle was $171^{\circ}(164$ to 176$)$ in the HTO group and $173^{\circ}$ (165 to 179) in the HCO group. After six weeks, the median HKA angle was $185^{\circ}$ (176 to 194) in the HTO group and $184^{\circ}$ (181 to 188) in the HCO group. In the HTO group, seven patients were within the range of $182^{\circ}$ to $186^{\circ}$ compared with 21 in the HCO group $(p<0.001)$. One year later, ten HTO patients were within this range while the HKA angulation in the HCO group was unchanged. At two years the numbers were 11 and 18, respectively.

We evaluated the clinical results on the Hospital for Special Surgery, Lysholm and Wallgren-Tegner activity scores, and patients completed part of the Nottingham Health Profile questionnaire. An impartial observer at the two-year follow-up concluded that all scores had improved, but found no clinical differences between the groups.

J Bone Joint Surg [Br] 1999;81-B:444-8.

Received 11 March 1998; Accepted after revision 17 August 1998

Medial osteoarthritis of the knee is associated with varus deformity and an abnormal load through the medial compartment. Proximal tibial osteotomy can restore the mechanical axis and correct the abnormal load. ${ }^{1,2}$ Good

G. Magyar, MD, Orthopaedic Surgeon

S. Toksvig-Larsen, MD, PhD, Orthopaedic Surgeon

A. Lindstrand, MD, PhD, Orthopaedic Surgeon

Department of Orthopaedics

T. L. Ahl, MD, Radiologist

Department of Radiology

University Hospital, S-221 85 Lund, Sweden.

P. Vibe, MD, Orthopaedic Surgeon

Department of Orthopaedics, County Hospital, S-281 25 Hässleholm, Sweden.

Correspondence should be sent to Dr G. Magyar.

(C)1999 British Editorial Society of Bone and Joint Surgery

0301-620X/99/38925\$2.00 long-term results depend on the ultimate correction, which is ideally $2^{\circ}$ to $8^{\circ}$ of valgus of the mechanical axis. ${ }^{3-6}$ There are several reports of good results achieved by closedwedge osteotomy, ${ }^{3-5,7-9}$ but this procedure is technically demanding. The outcome is unpredictable and the period of convalescence lengthy. ${ }^{7,9-11}$ In addition, access to the lateral compartment may be difficult after previous tibial osteotomy, $^{12,13}$ and even in the younger age group some surgeons carry out a primary arthroplasty rather than an osteotomy. $^{14-16}$ Open-wedge osteotomy by hemicallotasis (HCO) is simpler and requires a shorter rehabilitation period. $^{17,18}$

We have compared in a randomised, prospective study the results and complications of closed-wedge high tibial osteotomy (HTO) and HCO.

\section{Patients and Methods}

We randomly allocated 46 patients (14 women and 32 men) to either HTO $(n=25)$ or HCO $(n=25)$. The two groups were similar in age, gender, preoperative grade of arthritis and hip-knee-ankle angle (HKA) (Table I). The median age was 55 years (40 to 68) in the HTO group and 55 years (38 to 64$)$ in the HCO group. The median range of movement was $125^{\circ}$ (105 to 140 ) in the HTO group and $130^{\circ}$ (90 to $150)$ in the $\mathrm{HCO}$ group. Bilateral surgery was carried out on four patients, one of whom was randomised to HTO on both sides. The other three had HTO on one side and HCO on the other. There was a median interval of nine months (2.5 to 14) between the two operations. Surgeons of equal experience and skill carried out the procedures.

The indication for surgery was pain in younger, active patients with medial arthritis of grade 1 to $3 .{ }^{19}$ We aimed to achieve an overcorrection to an HKA of $4^{\circ}$ of valgus in both groups. The correction of $4 \pm 2^{\circ}$ of valgus was considered optimal.

Table I. Preoperative radiological assessment and median HKA for the patients allocated to HTO or HCO

\begin{tabular}{llcc}
\hline & \multicolumn{3}{c}{ Number of cases } \\
\cline { 3 - 4 } & & HTO $(\mathbf{n}=\mathbf{2 5})$ & HCO $(\mathbf{n = 2 5})$ \\
\hline Ahlbäck grade & 1 & 12 & 14 \\
& 2 & 6 & 8 \\
& 3 & 7 & 3 \\
Median HKA (range in degrees) & $171(164$ to 176) & 173 (165 to 179)
\end{tabular}

THE JOURNAL OF BONE AND JOINT SURGERY 
With patients standing weight-bearing, we evaluated radiologically the grade of arthritis and the degree of varus deformity. Measurements of the HKA angle were taken with the knee in slight flexion, and the values obtained were reasonably reproducible. ${ }^{20,21} \mathrm{~A}$ true lateral radiograph was obtained by superimposing one femoral condyle over the other, and the anteroposterior projection was taken at $90^{\circ}$ to this lateral plane. We calculated HKA angles using a ruler frame and a full-length radiograph which showed both hip and ankle, drawing lines from the centre of the femoral head and from the centre of the tibial surface of the ankle to the midpoint between the spines of the tibial eminence. ${ }^{22}$ The medial angle between these two lines gave the HKA angle. Angulation of less than $180^{\circ}$ was considered varus.

We measured the angular correction in the HTO group on the first postoperative day. It was defined as the difference between the preoperative and postoperative angles of the tibial plateau, measured as the angle between the tibial condyles and the tibial anatomical axis in the frontal plane. In the HCO group, correction was achieved gradually and the first comparison was made six weeks after surgery. At this time we removed the casts from patients in the HTO group and began rehabilitation. In the HCO group, external fixators remained in place.

We used the Hospital for Special Surgery (HSS) score, the Lysholm score and the Wallgren-Tegner activity score $^{23-25}$ for clinical assessment. Part 1 of the self-administered Nottingham Health Profile (NHP) questionnaire was used to obtain an appraisal of perceived personal health. ${ }^{26}$ The patients responded to 38 weighted statements covering six categories: energy, sleep, physical mobility, emotion, pain and social isolation. A minimum score of zero indicates that a patient experiences no problems in a particular category; the maximum score is 100 .

The four patients who had bilateral operations were only assessed for the first procedure. Consequently, the HTO group consisted of 22 patients and the HCO group of 24 . NHP assessments of two patients, one from each group, were excluded because of incomplete answers. In both groups a visual analogue scale (0 to 10$)$ was used to evaluate pain three and six weeks after operation. In the HCO group pain was also evaluated one and two weeks after surgery, during the initial distraction phase.

A follow-up examination was first carried out one year after operation. An outside observer conducted the followup at two-years. Before the examination, the relevant leg was covered to conceal the operative technique. The duration of periods of hospitalisation and convalescence were recorded. Two patients in each group who had retired at the time of operation were excluded from the evaluation of sick leave.

Descriptive statistics are given as median values (range). We used the chi-squared, Fisher's exact, and the MannWhitney $\mathrm{U}$ tests to compare the radiological assessments and the knee and pain scores of the two groups. The Wilcoxon signed-rank test compared changes in clinical scores, NHP or HKA angles within each group. A p value of $\leq 0.05$ was considered significant.

Closed-wedge osteotomy (HTO). We used a tourniquet to create a bloodless field. The peroneal nerve was identified and the lateral cortex of the tibia exposed. A cylinder of bone was removed from the fibula appropriate to the degree of planned correction. Using a reciprocal saw, a proximal osteotomy was performed 2 to $2.5 \mathrm{~cm}$ below the knee. With a guide instrument ${ }^{27}$ the distal osteotomy was carried out aiming at an overcorrection to $4^{\circ}$ of valgus. Once the bone wedge had been removed, the gap was closed and stabilised with a long-stepped bone staple. After closure of the wound a plaster cast was applied. Patients were allowed immediate weight-bearing. Casts were removed after 45 days (0 to 94). One patient was given an orthosis rather than a plaster cast immediately after the operation. In another the cast was exchanged after 17 days for an orthosis which the patient used for 28 days.

Hemicallotasis (HCO). We chose to use the OF-Garche fixator (Orthofix Srl, Bussolengo, Italy). Using a template, two pins were inserted about $2 \mathrm{~cm}$ below the joint line in the proximal tibial metaphysis and two in the diaphysis. They were 110 to $130 \mathrm{~mm}$ conical-threaded pins of the cortical type (Orthofix $6 / 5 \mathrm{~mm}$ ). The osteotomy was carried out with a reciprocal saw at the level of the distal third of the tibial tuberosity. It extended to about the medial $75 \%$ of the tibial circumference. The lateral cortex was left intact, acting as a hinge during the distraction phase. No fibular osteotomy was performed. Patients were allowed immediate weight-bearing. Angular distraction was initiated seven to ten days after surgery, and was controlled by measurements of the HKA. Once the planned degree of correction had been achieved, the fixator was locked. Patients returned ten weeks after surgery for radiological, ultrasonic and clinical examinations. Further follow-up visits were planned according to progress. When there was sufficient callus, the fixator was removed and the patient was encouraged to practise full weight-bearing. The pins were then removed in the outpatient department, without analgesia or sedation. The mean period of external fixation was 88 days (61 to 146). After operation prophylactic antibiotics were given over a median time of ten days (6 to 33). The patients were instructed to clean the pins and skin daily and to keep the pin wounds open. Any symptoms of pintrack infection were treated with antibiotics. We used the Otterburn classification ${ }^{28}$ to grade infections (Table II). Patients had unlimited access to the treating team.

Table II. The Otterburn classification of pin-track infections

\begin{tabular}{ll}
\hline Grade & Infection responded to \\
\hline 1 & Pin-site care \\
2 & Pin-site care and oral antibiotics \\
3 & Reposition of pin, external fixation continued \\
4 & $\begin{array}{l}\text { Removal of external fixation with local surgery to control } \\
\text { infection }\end{array}$ \\
5 & Grade 4, with addition of radiological sign of osteomyelitis \\
6 & Chronic osteomyelitis, sequestrum formation \\
\hline
\end{tabular}


Table III. The median HKA angle (degrees; range) six weeks after surgery and at the one-year and two-year follow-up

\begin{tabular}{llll}
\hline Follow-up & HTO & HCO & p value \\
\hline Six weeks & 185 (176 to 194$)$ & $184(181$ to 188$)$ & 0.84 \\
One year & 182 (174 to 193$)$ & $184(178$ to 190$)$ & 0.18 \\
Two years & 182 (174 to 192$)$ & $182(179$ to 189$)$ & 0.30 \\
\hline
\end{tabular}

Results

Table III shows the results of the radiological evaluation after operation. In the HTO group, the mean intraoperative correction was $12^{\circ}$ ( 4 to 20 ). Correction to $4 \pm 2^{\circ}$ of valgus was achieved in 16 of the 25 operations with correction to $4 \pm 4^{\circ}$ of valgus in 21 (Fig. 1).

At six weeks, the median HKA angle was $185^{\circ}$ (176 to 194 ) in the HTO group and $184^{\circ}$ (181 to 188) in the HCO group (Table III). Seven of the HTO and 21 of the HCO patients had HKA angles between $182^{\circ}$ and $186^{\circ}$. The difference was significant $(\mathrm{p}<0.001)$. The HKA angles decreased from $185^{\circ}$ to $182^{\circ}$ during the first year in the HTO group, but did not change in the HCO group $(\mathrm{p}<0.001)$. During the second postoperative year, there was no significant change in the HKA angles within the two groups. At the one-year follow-up (Fig. 2) ten of the HTO and 21 of the HCO group had HKA angles in the range $182^{\circ}$ to $186^{\circ}(\mathrm{p}=0.002)$. At the two-year follow-up (Fig. 3), 11 of the HTO group and 18 of the HCO group had HKA angles within this range.

In the $\mathrm{HCO}$ group, pain was classified as zero (0 to 5 ) one week after surgery and as 3 (0 to 10) during the distraction phase a week later. Three weeks after surgery it was zero (0 to 5$)$ in the HTO group and 2 ( 0 to 8$)$ in the HCO group $(p=0.09)$. After six weeks, it was zero in both groups ( 0 to 6 in the HTO group and 0 to 3 in the HCO group; $p=0.99)$. In both groups, the clinical scores were improved at the two-year follow-up, and the HSS, Lysholm and Wallgren-Tegner activity scores were similar (Table IV). The range of movement was $120^{\circ}$ (110 to 150) in the HTO group and $125^{\circ}$ (10 to 135) in the HCO group. We found no significant differences between values before and after operation or between the two groups.

Scores in the NHP categories of pain and physical mobility were improved in both groups and there were no significant differences between them (Table V). Both hospital stays $(\mathrm{p}<0.001)$ and convalescence periods $(\mathrm{p}=0.01)$ were shorter for patients in the HCO group (Table VI).

Complications of HTO. During the period of treatment there was a definite change in the HKA angle in four patients. In one, the angle increased from $185^{\circ}$ to $197^{\circ}$ during the period of fixation of the cast. No improvement had occurred six weeks after an attempt at closed reduction and prolonged immobilisation. Revision surgery was carried out 53 days after the primary operation. The lateral staple was removed. The valgus angle was decreased and held by two staples on the medial side. Intraoperative bone cultures confirmed deep infection

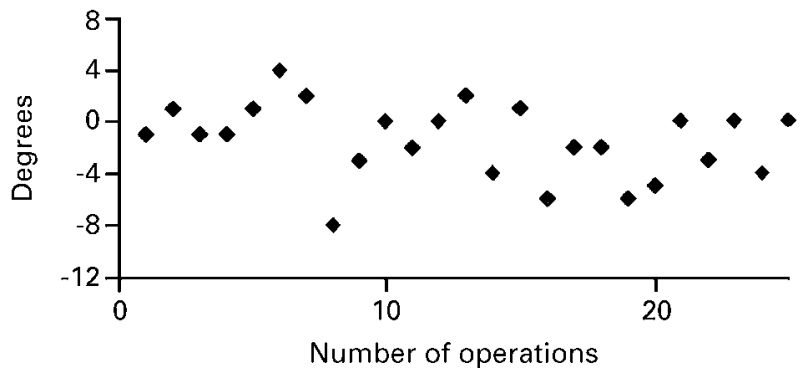

Fig. 1

Difference in degrees between planned and achieved correction, measured as the postoperative change in the angle of the tibial plateau after HTO.

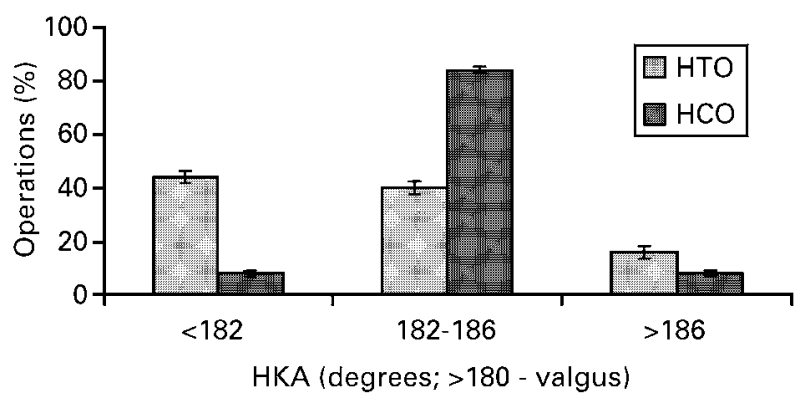

Fig. 2

HKA at the one-year follow-up given as the percentage (95\% CI) of operations. The difference between the two operative groups is significant $(\mathrm{p}=0.002)$.

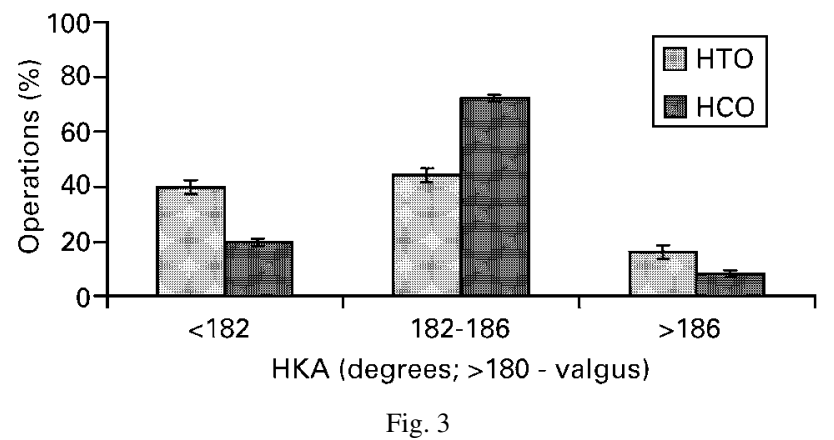

HKA at the two-year follow-up given as the percentage (95\% CI) of operations. The difference between the two operative groups is not significant.

Table IV. Median improvement (range) of clinical scores between preoperative assessment and two-year follow-up

\begin{tabular}{lccr}
\hline $\begin{array}{l}\text { Operative } \\
\text { technique }\end{array}$ & Score & & \\
\cline { 2 - 4 } & Preoperation & $\begin{array}{l}\text { Two-year } \\
\text { follow-up }\end{array}$ & p value \\
\hline HTO & $67(50$ to 80$)$ & $89(57$ to 98$)$ & $<0.001$ \\
HSS & $56(34$ to 78$)$ & $86(43$ to 100$)$ & $<0.001$ \\
Lysholm & $8(5$ to 10$)$ & $9(5$ to 13$)$ & 0.004 \\
Wallgren-Tegner & & & \\
HCO & $69(53$ to 83$)$ & $94(69$ to 100$)$ & $<0.001$ \\
HSS & $55(42$ to 80$)$ & $91(55$ to 100$)$ & $<0.001$ \\
Lysholm & $7(4$ to 9$)$ & $10(5$ to 13$)$ & 0.001 \\
$\quad$ Wallgren-Tegner & & & \\
\hline
\end{tabular}

THE JOURNAL OF BONE AND JOINT SURGERY 
Table V. Mean (range) improvement of NHP score from preoperative assessment to two-year follow-up

\begin{tabular}{lcrc}
\hline & Score & & \\
\cline { 2 - 4 } $\begin{array}{l}\text { Operative } \\
\text { technique }\end{array}$ & Preoperation & $\begin{array}{l}\text { Two-year } \\
\text { follow-up }\end{array}$ & p value \\
\hline HTO & $0(0$ to 100$)$ & $0(0$ to 61$)$ & 0.20 \\
$\quad$ Energy & $20(0$ to 49$)$ & $10(0$ to 53$)$ & 0.007 \\
$\quad$ Physical mobility & $\quad 83(0$ to 100$)$ & $8(0$ to 82$)$ & 0.002 \\
Pain & $11(0$ to 75$)$ & $11(0$ to 53$)$ & 0.031 \\
Sleep & $0(0$ to 64$)$ & $0(0$ to 64$)$ & 0.577 \\
Emotion & $0(0$ to 24$)$ & $0(0$ to 46$)$ & 0.75 \\
Social isolation & & & \\
HCO & $0(0$ to 100$)$ & $0(0$ to 82$)$ & 0.064 \\
$\quad$ Energy & $31(10$ to 53$)$ & $10(0$ to 31$)$ & $<0.001$ \\
Physical mobility $)$ & $83(18$ to 100$)$ & $8(0$ to 63$)$ & $<0.001$ \\
Pain & $33(0$ to 100$)$ & $6(0$ to 75$)$ & 0.001 \\
Sleep & $15(0$ to 100$)$ & $0(0$ to 36$)$ & $<0.001$ \\
Emotion & $0(0$ to 82$)$ & $0(0$ to 46$)$ & 0.125 \\
$\quad$ Social isolation & & & \\
\hline
\end{tabular}

Table VI. The median (range) number of days for hospital stay and sick leave after the two techniques

\begin{tabular}{lclc}
\hline & HTO $(\mathbf{n}=\mathbf{2 3})$ & HCO $(\mathbf{n}=\mathbf{2 3})$ & p value \\
\hline Sick leave $50 \%$ & $0(0$ to 158$)$ & $12(0$ to 224$)$ & 0.24 \\
Sick leave $100 \%$ & $132(55$ to 328$)$ & $90(17$ to 195$)$ & 0.01 \\
Hospital stay & $4(3$ to 8$)$ & $1(1$ to 4$)$ & $<0.001$ \\
\hline
\end{tabular}

with Enterobacter cloacae and the patient was treated with ciprofloxacin for four weeks. The osteotomy healed with an HKA angle of $193^{\circ}$ at the one-year follow-up. Clinical scores at two years indicated a good to excellent result. In a second patient, the HKA angle increased during the period of fixation of the cast from $186^{\circ}$ to $190^{\circ}$. Closed reduction was carried out and a cast maintained for 66 days in all. At the one-year follow-up, the HKA angle was $188^{\circ}$ and the clinical result at two years was considered to be fair to good. In the patient whose cast had been exchanged for an orthosis 17 days after surgery, the HKA angle increased from $184^{\circ}$ to $191^{\circ}$. The increased valgus angle was detected ten weeks after operation, by which time the osteotomy was considered healed. At the one-year follow-up, the HKA angle was $191^{\circ}$. Clinical scores at the two-year follow-up indicated a fair to good result. A fourth patient lost correction while the leg was in plaster. The HKA angle was $175^{\circ}$ six weeks after surgery. Closed reduction was carried out and the leg immobilised in plaster for a total of 59 days. At one year, the HKA angle was $174^{\circ}$. The patient developed lymphoedema below the knee. Clinical scores at the two-year follow-up indicated a fair to good result. The lymphoedema had decreased, but the patient was still having lymph therapy twice a week.

Complications of HCO. One patient was admitted to the orthopaedic ward for two days complaining of pain at the end of the distraction phase. There were no signs of any other complication. We recorded 18 pin-track infections, classified as grade 1 to 2 , in 15 patients; this is equal to a rate of pin infection of $18 \%$. The infections were localised to the tibial metaphysis in 14 patients. Patients received antibiotic treatment for 24 days (6 to 101). During the period of external fixation, antibiotics were administered once to three patients, twice to seven, three times to four, and four times to one. We encountered no deep infection or septic arthritis.

\section{Discussion}

Our results show that $\mathrm{HCO}$ is a reasonable alternative to HTO. The latter relieves pain effectively in arthritis of the medial compartment. ${ }^{3-5,8,9}$ Slight overcorrection of the mechanical axis gives the best long-term results, diminishing both the risk of recurrence of varus deformity and the need for revision surgery. The disadvantage of HTO is that it is technically demanding and calls for a long period of rehabilitation. This may explain the preference for unicompartmental or tricompartmental arthroplasty. ${ }^{14-16}$ It is easier to undertake $\mathrm{HCO}$, but neither the technique nor the standards for postoperative monitoring during the distraction and healing phases have yet been well described. ${ }^{17,18}$ In earlier studies of HTO the accuracy of correction has varied, according to the authors' own definition of the desired amount, between $22 \%$ and $98 \% .^{7,9-11,27}$ In our series, $84 \%$ of HKA angles were adjusted to between $180^{\circ}$ and $188^{\circ}$. We found that the HCO technique gave more precise and predictable results, and less patients lost correction during the first postoperative year.

Both bony deformity and ligamentous laxity may contribute to abnormal HKA angulation. Since the influence of ligamentous laxity is difficult to determine, assessment of the correction achieved by HTO is generally based on osseous correction of the total deformity. ${ }^{29}$ This may explain why there was a difference in the HKA angles immediately after surgery and six weeks later. The osseous correction of the HCO is progressive, and the correction achieved is assessed by repeated measurement of the HKA angle. Therefore the influence of ligamentous laxity is reduced and excessive overcorrection is less likely to occur.

Periods of hospital stay and convalescence were shorter in the HCO group. Despite better radiological results, we found no significant differences in the clinical results of the two groups, perhaps because they were too small for statistical evaluation. The clinical scores seemed to lack the sensitivity to detect differences in younger, active patients.

Prodromos, Andriacchi and Galante ${ }^{30}$ reported that in a group of patients with early loss of correction after HTO the peak adduction moments were not neutralised when assessed by gait analysis. In our HTO group, three of the four patients who had complications developed overcorrection during the time which they were immobilised in plaster. In the others there was notable loss of correction during the first postoperative year; the combination of a staple and a plaster cast was insufficient to maintain correction during the healing phase. The use of a plate for internal 
fixation may reduce this complication. Near the end of the distraction phase, several patients in the HCO group reported subjective improvement and greater comfort in the knee on walking. This suggests that a more individualised correction may be obtained using the HCO technique assuming that the optimal individual correction is normally distributed.

The incidence of pin-track infection in the HCO group may present a problem. Infection in the metaphysis may jeopardise later knee arthroplasty. Earlier studies report that there is an incidence of minor infections of $5 \%$ to $58 \%$ and of major infections of $2 \%$ to $20 \%$ when external fixators are used. $^{31,32}$ We found only minor infections perhaps because of the relatively long period of antibiotic prophylaxis and the aggressive use of antibiotics when indicated during the fixation period.

After HTO the complications were fewer, but more serious. Short of carrying out revision surgery, there were few ways to manage the loss of correction which occurred during the period of fixation. With $\mathrm{HCO}$ we obtained accurate correction and comparable clinical outcomes. Pintrack infection, which was not accompanied by clinical problems, was the only complication. Both the length of stay in hospital and the morbidity were reduced after the use of the HCO technique.

The authors thank Jonas Ranstam, BSc, PhD, CStat, for statistical advice, and gratefully acknowledge the contribution of members of the Lund University Medical Faculty, Lunds Sjukvårdsdistrikt, Stiftelsen för bistånd åt vanföra I Skåne, MFR (09509), Centrum för Idrottsforskning, Svenska Läkaresälliskapet.

No benefits in any form have been or will be received from a commercial party related directly or indirectly to the subject of this article.

\section{References}

1. Bauer GCH. Treatment of gonarthrosis. In: Frankel VH, ed. AAOS Instructional Course Lectures St Louis, etc; CV Mosby Co. 1982;31:153-65.

2. Maquet PGJ. The treatment of choice in osteoarthritis of the knee. Clin Orthop 1985;192:108-12.

3. Coventry MB, Bowman PW. Long-term results of upper tibial osteotomy for degenerative arthritis of the knee. Acta Orthop Belg 1982;48:139-56.

4. Coventry MB, Ilstrup DM, Wallrichs SL. Proximal tibial osteotomy: a critical long-term study of eighty-seven cases. J Bone Joint Surg [Am] 1993;75-A:196-201.

5. Odenbring S. Osteotomy for medial gonarthrosis. Thesis, Lund University, 1991:15-8.

6. Valenti JR, Calvo R, Lopez R, Canadell J. Long term evaluation of high tibial valgus osteotomy. Int Orthop 1990;14:347-9.

7. Hernigou Ph, Medevielle D, Debeyre J, Goutallier D. Proximal tibial osteotomy for osteoarthritis with varus deformity. J Bone Joint Surg [Am] 1987;69-A:332-54.

8. Ivarsson I. On treatment of medial gonarthrosis. Thesis, Linköping University, 1991: 33-50.

9. Koshino T, Morii T, Wada J, et al. High tibial osteotomy with fixation by a blade plate for medial compartment osteoarthritis of the knee. Orthop Clin North Am 1989;20:227-43.
10. Matthews LS, Goldstein SA, Malvitz TA, Katz BP, Kaufer H. Proximal tibial osteotomy: factors that influence the duration of satisfactory function. Clin Orthop 1988;229:193-200.

11. Vainionpää S, Läike $\mathbf{E}$, Kirves $\mathbf{P}$, Tiusanen $\mathbf{P}$. Tibial osteotomy for osteoarthritis of the knee: a five to ten-year follow-up study. $J$ Bone Joint Surg [Am] 1981;63-A:938-46.

12. Katz MM, Hungerford DS, Krackow KA, Lennox DW. Results of total knee arthroplasty after failed proximal tibial osteotomy for osteoarthritis. J Bone Joint Surg [Am] 1987;69-A:225-33.

13. Windsor RE, Insall JN, Vince KG. Technical considerations of total knee arthroplasty after proximal tibial osteotomy. J Bone Joint Surg [Am] 1988;70-A:547-55.

14. Diduch DR, Insall JN, Scott WN, Scuderi GR, Font Rodriguez D. Total knee replacement in young, active patients, long-term follow-up and functional outcome. J Bone Joint Surg [Am] 1997;79-A:575-82.

15. Gill GS, Chan KC, Mills DM. 5- to 18-year follow-up study of cemented total knee arthroplasty for patients 55 years old or younger. J Arthroplasty 1997;12:49-54.

16. Stern SH, Bowen MK, Insall JN, Scuderi GR. Cemented total knee arthroplasty for gonarthrosis in patients 55 years old or younger. Clin Orthop 1990;260:124-9.

17. Fowler JL, Gie GA, MacEachern AG. Upper tibial valgus osteotomy using dynamic external fixator. J Bone Joint Surg [Br] 1991;73-B: 690-1.

18. Magyar G, Toksvig-Larsen S, Lindstrand A. Open wedge tibial osteotomy by callus distraction in gonarthrosis: operative technique and early results in 36 patients. Acta Orthop Scand 1998;69:147-51.

19. Ahlbäck S. Osteoarthrosis of the knee: a radiographic investigation. Acta Radiol 1968;Suppl 277:7-72.

20. Odenbring S, Berggren AM, Peil L. Roentgenographic assessment of the hip-knee-ankle axis in medial gonarthrosis: a study of reproducibility. Clin Orthop 1993;289:195-6.

21. Sanfridsson J, Ryd L, Eklund K, Kouvaras Y, Jonsson K. Angular configuration of the knee: comparison of conventional measurements and the QUESTOR precision radiography system. Acta Radiol 1996; 37:633-8.

22. Siu D, Cooke TDV, Broekhoven LD, et al. A standardized technique for lower limb radiography: practice, applications, and error analysis. Invest Radiol 1991;26:71-7.

23. Insall JN, Ranawat CS, Aglietti P, Shine J. A comparison of four models of total knee-replacement prostheses. J Bone Joint Surg [Am] 1976;58-A:754-65.

24. Lysholm J, Gillquist J. Evaluation of knee ligament surgery results with special emphasis on use of a scoring scale. Am J Sports Med 1982;10:150-4.

25. Tegner Y. Cruciate ligament injuries in the knee: evaluation and rehabilitation. Thesis, University of Linköping, Sweden, 1985.

26. Jenkinson C, Fitzpatrick R, Argyle M. The Nottingham Health Profile: an analysis of its sensitivity in differentiating illness groups. Soc Sci Med 1988;27:1411-4.

27. Odenbring S. A guide instrument for high tibial osteotomy. Thesis, Lund University, 1991:24-7.

28. Saleh M, Scott BW. Pitfalls and complications in leg lengthening: the Sheffield experience. Semin Orthop 1992;7:207-22.

29. Paley D, Maar DC, Herzenberg JE. New concepts in high tibial osteotomy for medial compartment osteoarthritis. Orthop Clin North Am 1994;25:483-98.

30. Prodromos CC, Andriacchi TP, Galante JO. A relationship between gait and clinical changes following high tibial osteotomy. J Bone Joint Surg [Am] 1985;67-A:1188-94.

31. Green SA. Complications of external skeletal fixation. Clin Orthop 1983;180:109-16.

32. Pouliquen JC, Ceolin JL, Langlais J, Pauthier F. Upper metaphyseal lengthening of the tibia by callotasis: forty-seven cases in children and adolescents. J Pediatr Orthop 1993;2:49-56. 